\title{
Abstract
}

Prisons are institutions where power and control are complex issues which have a significant affect on nursing. This paper focuses on the development of a framework to illuminate an understanding of the way in which power, discourse and knowledge connect within the prison setting, and thus impact on both the emotional labour and professional practice of the prison nurse. Central to developing this framework is reference to a study which explored the emotional labour of prison nurses. In affecting the complex knowledge/power relationships within the prison health care setting, regular high quality clinical supervision is suggested as one way in which prison nurses can be supported in challenging the regimes of truth that underpin the dominant discourses affecting their practice, and hence their levels of emotional labour.

Key Words clinical supervision, emotional labour, Foucault, knowledge/power connection, prison

\section{Prison Nursing: The Knowledge/Power Connection}

\section{ELIZABETH CLARE LOUISE WALSH}

\section{Introduction}

This paper presents a framework to illustrate the knowledge/ power connection in the prison health care setting. It was developed as part of a study in which the emotional labour of nurses working in HM Prison Service in England and Wales was examined (Walsh E, 2007, unpublished thesis). The knowledge/power connection considered in this paper, and viewed through the lens of a Foucauldian postmodernist philosophy highlights the way in which knowledge and power influence nurses working in this setting, taking into consideration the dominant discourses to which they are exposed and the resultant impact on their levels of emotional labour. The study from which this framework was developed is not discussed in detail in this paper, however, brief detail of the study is provided to enable the reader to understand the world of the prison nurse and to illuminate the development of the proposed framework. [1]

\section{Exploring the emotional labour of prison nurses}

Nurses working in prison in England and Wales can be seen to have a dual role, encompassing both health care and security. The competing priorities of care and custody within the prison setting can often place the nurse in direct conflict with the prison system. Couple this with the need for the nurse working with prisoners to maintain a professional, effective approach to practice, and it can be seen that these nurses are undertaking significant emotional labour. Mann identifies three components of emotional labour: "The faking of emotion that is not felt; and/or the hiding of emotion that is felt, and the performance of emotion management in order to meet expectations within a work environment" ${ }^{\prime \prime}$.[2 p208] The impact of prolonged exposure to high levels of emotional labour can have a significant 
effect on the well being of the nurse.[3]

In order to examine the emotional labour of these nurses, a qualitative, reflexive methodology was adopted with a postmodern philosophical foundation. Phase one of the study involved semi-structured interviews with nine qualified nurses from three adult prisons; two male establishments and one female. In phase two of the study, two of these nine nurses entered into a supervisory relationship with me, the researcher, whereby monthly clinical supervision sessions were held with both nurses separately, over six months. A discourse analysis was undertaken throughout this study, using transcripts from the interviews, my own reflective research diary, documentary evidence, and notes made from clinical supervision sessions. In addition, my own reflections and experience as a prison nurse was included.

Findings from this study suggest that the nurse working in prison experiences emotional labour as a consequence of four key relationships: the relationship with the prisoner patient, the relationship with officer colleagues, and the relationship with the Institution. The fourth relationship, and perhaps that which causes the most significant emotional stress for the nurse, is that which they have with themself. This 'intranurse' relationship is characterised by the contradictory discourses the nurse engages with internally. This relationship involves ongoing internal dialogue between the two selves of the nurse: the professional self and the emotional 'feeling' self. In order to help manage emotional labour, it is suggested that the development of emotional intelligence through clinical supervision and reflective practice is of significant benefit.

The focus of this paper is the proposal of a framework to illustrate and guide understanding of the knowledge/power connection in the prison nursing arena, however, it is suggested that the following discussion of postmodernism is important, as it serves to contextualise my position both as researcher and participant in the study from which the framework is drawn.

\section{Postmodernism}

According to Mautner, postmodernism can mean many different things.[4] The term is used in architecture, in contemporary culture and the arts and in philosophy; hence, Mautner and Alvesson both highlight the need for clarity of meaning in any writings claiming to use a postmodern perspective. [4,5] However, Rodgers, in attempting to provide a definition, asserts that "this is a nearly impossible task because the very essence of postmodernism would seem to eschew a single definition'". [6 p131] Burnard suggests that, because postmodernism is against systems building and the development of grand theories, definition is problematic. He continues to suggest that postmodernism positively avoids definition, as to define it would be to "force it to commit itself, to state itself positively". [7 p241] Rodgers suggests that, although there is no single definition that can convey intent and meaning, there is one basic tenet of postmodernism which "characterises the domain of the ideology".[6 p133] She provides the statement 'the center does not hold' as what she terms 'the rallying cry of postmodernists'. Although this is viewed as one aspect of postmodern thinking, Alvesson highlights others such as the centrality of discourse; fragmented identities; the critique of the idea of representation; the loss of foundations and master narratives; and the knowledge/power connection as the central themes underpinning postmodern thinking.[5] It is this knowledge/power connection that is developed in this paper and viewed as an effective way to assist in understanding the roots of emotional labour and clinical practice of nurses working in prison.

\section{The centrality of discourse}

Alvesson refers to discourse as: 'Language use anchored in an institutional context, expressing a fairly structured understanding or a line of reasoning with active, productive effects on the phenomenon it claims to understand 'neutrally'". [5 p48] He continues to suggest that discourses not only structure the world but also structure the person's subjectivity and provide them with a place in the world and a social identity. Rodgers suggests that discourse is not limited to language but rather that it goes beyond it, as a statement is not merely words, but 'an interaction between the speaker and the listener'. ${ }^{\prime} 6$ p134]

An appreciation of the importance of discourse in understanding phenomena is central to this study. The stories of the nurses involved in my study provide an insight into how prison nursing 'is' in the prison setting for these nurses, and provides it with an awareness of where the nurse is placed within the context of the prison. An examination of the emotional labour of the prison nurse is only possible if the nature of the discourse within which the nurse is placed is made explicit.

\section{Fragmented identities}

According to Alvesson, "Postmodernism rejects the notion of the autonomous, self-determining individual with a secure unitary identity as the centre of the social universe... Generally the human subject is viewed as an effect of, or at least strongly constrained by and constituted within, discourse".[5 p50] It 
is my belief that all people are individuals with their own views, thoughts and feelings that shape their identity which leads me to resonate with the notion of fragmented identities. Indeed, when thinking about this belief from a postmodern perspective, this goes one stage further in suggesting that people are a result of being involved in and constructing their own discourse and it is in these discourses that the feelings, views and thoughts of people are articulated.

In examining this stance from a Foucauldian perspective, I view the use of analysing and examining discourses as a useful means of looking at the way in which the use of power affects the situation in which prison nurses find themselves. Underpinning this idea, I suggest that the values, thoughts and beliefs inherent in the nurse may be shaped as a result of previous and present power relations. Francis states that the understanding of power embedded in discourse "helps to explain the ways in which an individual's power position appears to shift depending on the interactive environment".[8 p22]

\section{The critique of the idea of representation}

Postmodern philosophers question the idea of representation, i.e. the ability to represent objects using language. It is suggested that a general objective reality is elusive because objects can only be defined in terms of the object for the person to whom the object is significant. For example, my experiences of prison and hence my ability to describe it as an objective reality is flawed because to propose a general perception of 'prison' would be wrong - it is only my perception as it pertains to me that I am describing. That of an ex-prisoner would be very different. Therefore, the meaning of prison will be different to all those who have experienced it in whatever form (shaped and influenced by power and discourse) and therefore the meaning will never be final. It will always be "incomplete and indeterminate".[5 p53]

The idea of representation and its meaning in a postmodernist study means that the notion of emotional labour and the narratives of those nurses involved in the study may only be pertinent to those nurses, at that time, in that context. This does not mean to say that what we learn from them will be useless information; far from it. I feel that the data enable and support further study of emotional labour in prisons and, indeed, can help inform the training and development of both new and existing staff in this setting. As Alvesson \& Skoldberg suggest, "The study of suitable (well-thought out) excerpts from this reality can provide an important basis for a generation of knowledge that opens up rather than closes, and furnishes opportunities for understanding, rather than establishing 'truths'". [9 p5]

\section{The loss of foundations and master narratives}

Alvesson suggests that the postmodern school of thought rejects grand/master narratives and proposes that there is not one single truth but that there are many truths, developed and sanctioned from within the context that they are generated. [5] A practical example of this can be seen in Ceci.[9] In his foundational work, 'The Postmodern Condition: A Report on Knowledge', Lyotard asserts that "postmodernism is incredulity towards metanarratives".[11 pxxiv] In rejecting the metanarrative, or one truth, Lyotard offers the view that discourses of learning are "taken up not from the point of view of their immediate truth value, but in terms of the value they acquire by virtue of occupying a certain place in the itinerary of Spirit or Life - or if preferred, a certain position in the

Figure 1: The knowledge/power connection as viewed from a Foucauldian perspective

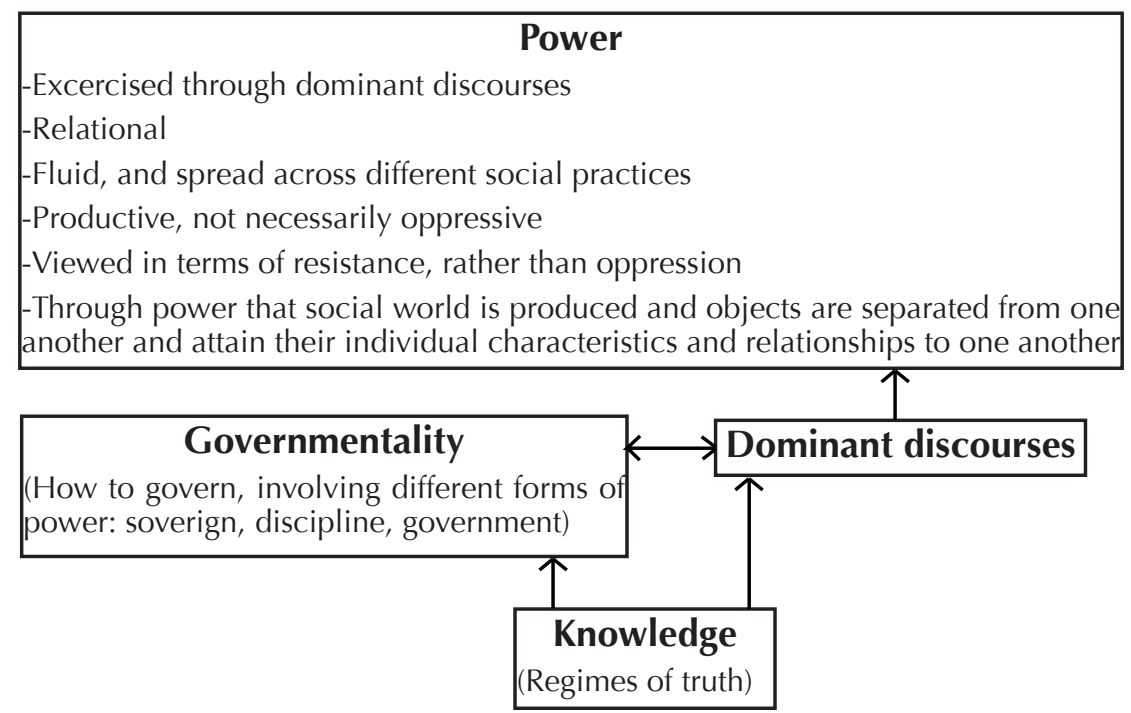


Encyclopaedia recounted by speculative discourse". [11 p35] In essence, placing certain discourses in higher regard than others leads to an automatic acceptance that they must be 'the truth'. The work of Lyotard has been enlightening for me in conducting this study in terms of questioning my own perspectives on truth. However, I have also considered my reaction to Lyotard's seminal work and questioned whether Lyotard himself is suggesting a metanarrative.

\section{The knowledge/power connection}

From a Foucauldian perspective where power is viewed through discourse, there are many levels that must be considered. There are power relations evident at all levels within the prison setting which affect an individual's understanding of their world, e.g. the nurse and the institution; the nurse and the multidisciplinary team; the multidisciplinary team and the institution; the nurse and the prisoner patient; between the nursing staff themselves; and the relationship between the researched and the researcher.

According to Manias \& Street, power has traditionally been viewed in terms of the 'juridico-discursive' model based on three assumptions: power is possessed; it flows from a centralised source from top to bottom; and it is primarily oppressive.[12] However, from a Foucauldian perspective, power is not directly viewed in these terms as it can be constructive and does not necessarily flow from top to bottom. Foucault did not think that power is possessed as such but that it is exercised through the dominant discourses of social institutions.[12] As such, Irving states that, "Discourse is the medium for transmitting power/knowledge".[13 p406] Alvesson cites Foucault who suggests that it is not the power that one possesses or acquires that is of interest but that these appearances of power are the outcome of more fundamental power relations, which can be seen through the discursive practices and dominant discourses surrounding people and institutions. [5] Alvesson contends that the discursive formation is "the combination of a set of linguistic distinctions, ways of reasoning and material practices that together organise social institutions and produce particular forms of subjects". [5 p56] It is with this in mind that the analysis in this study addressed the narrative not only through interview, but also through documentary evidence, data from clinical supervision sessions and reflections in my own reflective diary.

Power and knowledge, according to Foucault, are inextricably linked because it is knowledge that underpins dominant discourses. As Manias \& Street state, "Knowledge reinforces and supports existing regimes of truth".[12 p53] It is these regimes of truth within institutions that underpin the dominant discourse of the institution and subsequently how the institution and its population are controlled. Irving states that power and knowledge "mutually condition each other so that, as ideas become accepted as knowledge or "truth", they can delimit the discussion of other possibilities". [13 p406]

There are clear links here with the notion of reflective practice in so much as it is the reflection on and in practice that challenges accepted knowledge and instigates changes in both practice and power relations amongst practitioners. The promotion of reflective practice through clinical supervision and qualitative interviewing alters power relations amongst practitioners and the institution within which they practice. As Blackburn so eloquently states, "Reflection enables us to step back, to see our perspective on a situation as perhaps distorted or blind, at the very least to see if there is argument for preferring our ways, or whether it is just subjective".[14 p11] Although this perspective highlights the transformatory power of reflection, I suggest that this is something that those

Figure 2: Four key relationships

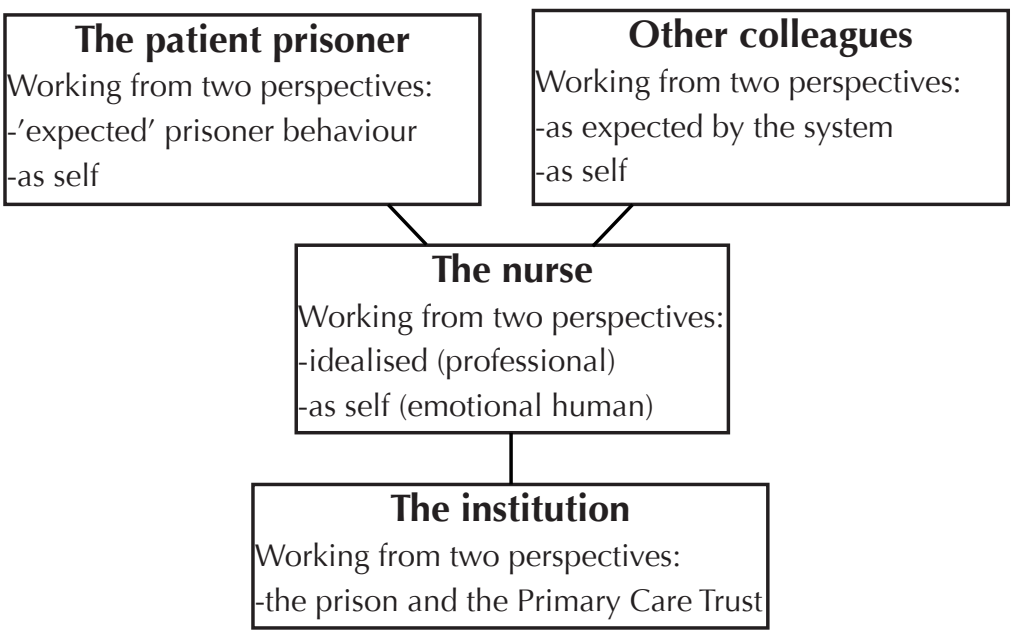


who practice in an oppressive institution or who are less than confident in their own positions may find challenging.

The concept of governmentality has been used in the literature to examine nursing as a health profession[15] and in understanding the position of nursing in the correctional forensic psychiatric setting $[16,17])$. Irving defines governmentality as "the way in which the conduct of government operates through the establishment of the moral obligation to self-govern".[13 p406] She compares this to the notion of sovereign power in which obedience is based on "fear of the consequences of disobedience".[13 p406] However, Holmes and Gastaldo suggest that the notion of governmentality can be viewed as a tripartite, complex system of power relations between sovereign power, disciplinary power and government, where sovereign power is exercised through repression and domination; disciplinary power through surveillance, punishment and rewards; and government power, which is rooted in the dominant discourse of moral obligation to self-govern.[15] This complex power relation needs to be unravelled when examining the notion of emotional labour of prison nurses as they encounter all three forms of power in their daily practice, affecting their internal feelings, their practice, their relationship with patients and other members of the multidisciplinary team, and their position within the institution and the systems in which they work.

As this diagram shows, from a Foucauldian perspective, knowledge underpins the dominant discourses through which power is applied. Therefore, it is important to be aware of the way in which knowledge is developed, given its key role in underpinning dominant discourse. Please refer to Figure 1 on page 9.

\section{The prison nurse: key relationships}

I suggest that the way in which the nurses in this study experienced and worked with emotional labour is evident through four key relationships: the relationship with the prisoner patient; the relationship with discipline colleagues; and their relationship with the prison as an institution, governing their overall practice. The fourth relationship, and perhaps that which is most significant, is the relationship the nurse engages in internally, with themselves. Given the relationships with which the prison nurse engages, it must also be noted that those with whom they engage also operate on both an external and internal level. As the focus of this work is the nurse, the operation of the other actors is not under analysis but is important to recognise.

In order to provide a visual representation of my thinking, the following figure illustrates these relationships and their interactions with one another. Please refer to Figure 2 on page 10 .

The effect of these relationships on the nurse, both internally and externally, impacts on the care they give and the way in which they practice. These relationships will also affect how they feel both internally and in their public displays. Therefore, the web of relationships within which the nurse is

\section{Figure 3: The prison nurse knowledge/power connection}

Power
-Excercised through dominant discourses
-Relational
-Fluid, and spread across different social practices
-Productive, not necessarily oppressive
-Viewed in terms of resistance, rather than oppression
-Through power that social world is produced and objects are separated
from one another and attain their individual characteristics and
relationships to one another

\begin{tabular}{|l|l|}
\multicolumn{1}{|c|}{ Governmentality } \\
-Concerns how to govern \\
-Involves different forms of power: e.g., sovereign, discipline, \\
government \\
-Concepts central to governmentality include: surveillance; \\
pastoral power; domination; self government
\end{tabular}


involved is what I believe necessitates their emotional labour. As Hochschild notes, "This labour requires one to induce or suppress feeling in order to sustain the outward countenance that produces a proper state of mind in others".[18 p7] Each relationship will necessitate the nurse to engage in emotional labour, be it to ensure the prisoner patient feels confident in the nurse's ability, for example, or the prison officer to feel as though the nurse understands the officer's perspective. I suggest that the relationship with the institution affects the emotional labour of the nurse on a more internal level, e.g. the routine of the prison (imposed by the institution) may restrict the nurse's ability to undertake particular care, which may cause the nurse conflict.

If these relationships are at the core of the emotional labour of the prison nurse, I suggest that the nurses' own levels of emotional intelligence dictate the way in which they manage the emotional labour. From the perspective of Salovey \& Mayer, emotional intelligence is "the subset of social intelligence that involves the ability to monitor one's own and other feelings and emotions, to discriminate against them and to use this information to guide one's thinking and actions".[19 p189] I therefore suggest that in order to undertake emotional labour the prison nurse must be able to monitor their own and others' emotions and feelings and be able to use the information to guide their own actions. Therefore, the nurses' ability to undertake emotional labour effectively is determined by their level of emotional intelligence.

\section{Power}

In order to place the ideas I have posited concerning the relationships of the nurses with others and themselves into focus, it is important to discuss the Foucauldian perspective of power as it relates to nurses and their relationships. I have mentioned the relationships with which the nurse engages, which demonstrate the underlying causes and effects of emotional labour upon the prison nurse. However, in addition to consideration of emotional labour and, hence, emotional intelligence, there is a need to contemplate the power relations inherent in the practice of the prison nurse, as these power relations are affected by the dominant discourses, accepted knowledge and processes of governmentality which are central to practice in the prison setting. As Holmes \& Gastaldo, suggest, "Power acts upon individuals, and they in turn act upon others. Therefore power is relational". [15 p559] The analysis undertaken in this study considered these power relations carefully, given the way in which power flow affects all aspects of the prison nurses' practice.

Not only are the relationships between the nurse and the prisoner patient/colleagues and institution subject to consideration from this Foucauldian perspective but also, importantly, the relationship nurses have with themselves. Holmes \& Gastaldo suggest that, "The construction of the self (subjectivity) is linked to established forms of knowledge and institutionalised practices. Self is not an essence; it is created by the influence of multiple forms of power".[15 p559] It is therefore natural to consider the power relations inherent

Figure 4: The potential impact of clinical supervison \& reflection on the knowledge/power connection in prison

Power
-Excercised through dominant discourses
-Relational
-Fluid, and spread across different social practices
-Productive, not necessarily oppressive
-Viewed in terms of resistance, rather than oppression
-Through power that social world is produced and objects are separated
from one another and attain their individual characteristics and
relationships to one another

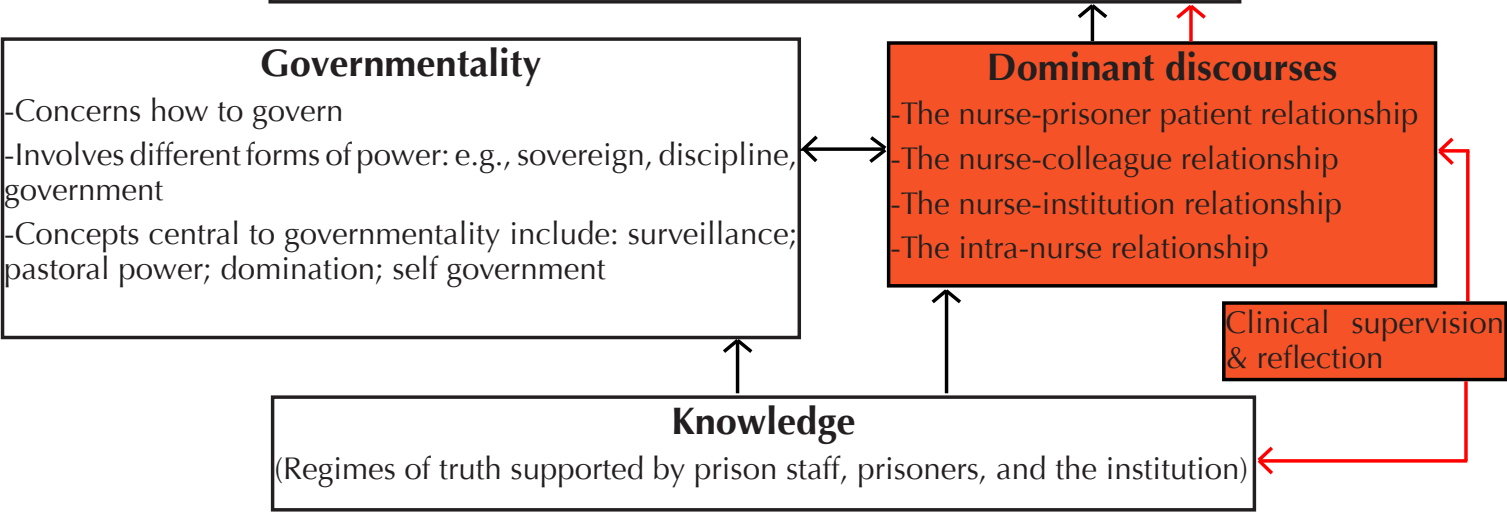


within the world of the prison nurse in terms of the dominant discourses they are engaged with, when one is exploring their space and practice in relation to their emotional labour.

If we consider the diagrammatic representation of the relationship between power, governmentality, dominant discourses and knowledge as discussed previously, it can now be developed further to take into account the relationships entered into by the prison nurse and demonstrate the complexity of the prison nurses' situation. Please refer to Figure 3 on page 11.

In light of the findings of this study, and further reflection on the work since the completion of the study, this diagrammatical representation of the knowledge/power connection in prison can now be further developed. Please refer to Figure 4 on page 12 .

If the prison nurse engages fully in regular, high quality clinical supervision and reflection on practice, I suggest that the dominant discourses which shape the way in which they work will, over time, change. As the nurse becomes more empowered, the regimes of truth that underpin the dominant discourses will also develop to meet the professional position of the nurse. In becoming more empowered and able to influence the four key relationships, I suggest that power relations will also begin to transform. Figure 4 highlights the potential impact of reflection and clinical supervision on the knowledge/power connection in prison.

\section{Conclusion}

The knowledge/power connection in prison nursing is complex, and impacts significantly on the practice of the nurse. Accepted knowledge within the prison culture, underpinned by 'regimes of truth' supported by prison staff, prisoners and the institution underpin the dominant discourses for the prison nurse, and are therefore enmeshed within the four relationships described. It is suggested that these regimes of truth, or accepted knowledge within the prison setting can be challenged by nurses who are well supported through effective clinical supervision.

However, engaging prison nursing staff in clinical supervision is not without its challenges. Walsh et al discuss the challenges to implementing and developing clinical supervision in the prison culture however, of note here, is experience of significant levels of suspicion and cynicism within the culture, which can be typical in closed organisations, when attempting to develop nursing practice.[20,21,22] It is suggested that cynicism and suspicion manifest themselves as barriers to clinical supervision and open reflection on practice as a result of what Menzies Lyth refers to as a defence against anxiety.[23]

I am not suggesting that my interpretation of the knowledge/ power connection within prison nursing is the same for all prison nurses in all prisons. I present this model as a framework to be built upon through further consideration and reflection by researchers, educationalists and practitioners in prison health care settings. I invite you to read it, deconstruct it and reconstruct it in order to make your own sense of it. It is through this deconstruction and reconstruction that I hope new perspectives on this concept, and perhaps new practices may emerge.

As Michel Foucault suggested at the beginning of a lecture series, "I would be very pleased if at the end of each lecture you would voice some criticisms and objections so that, insofar as possible and assuming my mind is not yet too rigid, I might gradually adapt to your questions and thus at the end of these five lectures we might have done some work together, or possibly made some progress"..[24 p1]

\section{References}

1.Walsh E. The emotional labour of prison nurses in Her Majesty's (HM) Prison Service. Journal of Forensic Nursing, In press.

2.Mann S. 'People-work': emotion management, stress and coping. British Journal of Guidance \& Counselling 2004; 32(2):205-21.

3.Walsh E. Prison nursing: its time to 'water the flowers'. British Journal of Nursing 2009; 18(4):218

4.Mautner T. The Penguin dictionary of philosophy. London: Penguin Books; 2000.

5.Alvesson M. Postmodernism and social research. Buckingham: Open University Press; 2002.

6.Rodgers BL. Developing nursing knowledge: philosophical traditions and influences. Philadelphia: Lippincott, Williams and Wilkins; 2005.

7.Burnard P. Carl Rogers and postmodernism: challenges in nursing and health sciences. Nursing and Health Sciences 1999; 1:241-7.

8.Francis B. Poststructuralism and nursing: uncomfortable bedfellows? Nursing Inquiry 2000; 7:20-8.

9.Alvesson M, Skoldberg K. Reflexive methodology: new vistas for qualitative research. London: Sage; 2002.

10.Ceci C. Nursing, knowledge and power: a case analysis. 
Social Science and Medicine 2004; 59:1879-89.

11.Lyotard JF. The postmodern condition: a report on knowledge. Manchester: Manchester University Press; 1984.

12. Manias E, Street A. Possibilities of critical social theory and Foucault's work: a toolbox approach. Nursing Inquiry 2000; 7:50-60.

13.Irving K. Governing the conduct of conduct: are restraints inevitable? Journal of Advanced Nursing 2002; 40(4):40512.

14.Blackburn S. Think, Oxford: Oxford University Press; 2006.

15. Holmes D, Gastaldo D. Nursing as a means of governmentality. Journal of Advanced Nursing 2002; 38(6):557-65.

16. Holmes D. Police and pastoral power: governmentality \& correctional forensic psychiatric nursing. Nursing Inquiry 2002; 9(2):84-92.

17. Holmes D. Governing the captives: forensic psychiatric nursing in corrections. Perspectives in Psychiatric Care 2005; 41(1):3-13.

18. Hochschild A. The managed heart. London: University of California Press; 1983.

19.Salovey P, Mayer JD. Emotional intelligence. Imagination, Cognition and Personality 1990; 9:185-211.

20.Walsh E, Dilworth S, Freshwater D. Establishing clinical supervision in prison health care settings; a report for offender health. Department of Health, Bournemouth: Bournemouth University; 2007.

21.Freshwater D, Walsh L, Storey L. Prison health care: developing leadership through clinical supervision. Nursing Management 2001; 8(8):10-13.

22. Freshwater D, Walsh L, Storey L. Prison health care part 2: developing leadership through clinical supervision. Nursing Management 2002; 8(9):16-20.

23. Menzies LI. Containing anxiety in institutions, selected essays, volume 1. London: Free Association Books; 1988.

24.Faubion JD. Michel Foucault, power, essential works of Foucault 1954-1984. London: Penguin; 2002.
Contact Information for Author:

Elizabeth Clare Louise Walsh, PhD, MSc, RGN

Senior Lecturer

University of Leeds

School of Heathcare

Baines Wing, PO Box 214

Leeds, LS2 9UT, West Yorkshire

United Kingdom

Email:e.walsh@leeds.ac.uk 